Males constituted $60.9 \%$ of cases. Children and elderly accounted for $32.5 \%$ and $13 \%$. A half of injuries occurred during leisure. Most injuries occurred on homestead lands (20.1\%), inside of dwellings (16.3\%) and on streets (7.1\%) during walking (30.2\%). The most common accident mechanisms were "have slipped" (16.0\%); error or loss of control when dealing with object, person or animal (15.7\%); "have stammered/stumbled" (13.9\%). The most common injury mechanisms were punch/kick due to fall after having slipped/stammered/stumbled (23.7\%), punch/kick due to contact/collision with an object in motion (9.2\%) and punch/kick due to due to impacts of human or animal. Most common external injury-related factor was ice-covered surface (11\%).

More injuries occurred on Sundays (17\%) than during other days. Use of alcohol 24 hours prior to trauma was reported by $28.1 \%$ of cases.

Conclusions Children and men and are most vulnerable groups. Preventive interventions should address leisure, domestic and other routine activities on homestead lands, in dwellings, and on the streets. Removal of slippery surfaces and promotion of antislip devices should be considered. Special emphasis should be given to reduction of alcohol use.

\section{DEVELOPMENT AND IMPLEMENTATION OF SAFE SCHOOLS IN AUSTRIA OUR ROAD TO SUCCESS}

${ }^{1}$ Sabine Distl, ${ }^{1}$ Peter Spitzer, ${ }^{2}$ Gudula Brandmayr, ${ }^{3}$ Brigitte Stricker. ${ }^{1}$ Safe Kids Austria/Grosse Schuetzen Kleine, Austria; ${ }^{2}$ Rein Lower and Upper Secondary School, Austria; ${ }^{3}$ Lannach Primary School, Austria

10.1136/injuryprev-2016-042156.233

Background We initiated and designed Safe School Communities, developed structures for implementation and evaluation in close cooperation with two different types of schools: Lannach Primary School and Rein Secondary School.

Description The first step was to motivate responsible persons of the advantages to becoming a designated Safe School. Together with them the second step was to establish a Steering Committee comprising all stakeholders and relevant representatives for safety in the schools and their community.

Results Each Safe School Committee has been developing programs for all ages and genders, with specific safety programs for those most at risk of injury.

Lannach Primary School was designated as International Safe School in May 2015. The data and evaluation of the developed and realised programs prove that their initiatives are effective.

Rein Secondary School also established a board of pupils - the elected Health and Safety School Representatives (two from each class) - to address the needs of students. During his site visit to the school in May 2015 Max Vosskuhler made the following statement: 'Rein is easily the best example of what International Safe Schools is trying to do. Their faculty, students and staff showed clear commitment and understanding.' The application to be designated as the first Safe School at the secondary level in Austria is the next step.

Conclusions It is helpful to implicate approved methodologies and follow the International Indicators for Safe Schools.

Lannach Primary School as the first International Safe School in Austria has a leading role, which makes it easier to share successful projects and programs with other schools - especially within the Safe Children Community Deutschlandsberg.

To develop and realise projects it is adjuvant to have additional financial support. The Austrian Workers Compensation
Board and the Styrian Government are relevant partners of Safe Kids Austria assisting these two pilot schools.

\section{REDUCING VISITS TO LOCAL HEALTH CARE BY ONE THIRD SAFETY PROMOTION EFFORTS IN WESTERN SWEDEN}

${ }^{1}$ Robert Ekman, ${ }^{2}$ Diana Stark Ekman, ${ }^{3}$ Jan Schyllander, ${ }^{4}$ Lothar Schelp. ${ }^{1}$ Orebro University, Sweden; ${ }^{2}$ University of Skovde, Sweden; ${ }^{3}$ Swedish Civil Contingencies Agency, Sweden; ${ }^{4}$ Karolinska Institutet, Sweden

\subsection{6/injuryprev-2016-042156.234}

Background Surveillance and analyses of unintentional injuries can help prioritise community prevention efforts. Community based safety promotion programs aimed at reducing injuries high-risk groups, including children, elderly and people in traffic environments, have been ongoing in the Swedish communities of Falkoping and Lidkoping (31,000 and 38,000 inhabitants respectively) over the past three decades (both are designated as Safe Communities).

Methods This study describes changes in local patterns for unintentional injuries resulting in outpatient visits to health care clinics and emergency rooms, hospitalizations and deaths, comparing information from two different study periods, 1978 and 2008. Injury cases were analysed, and confidence intervals were derived. Data for outpatient injuries were provided from the Skaraborg Injury Registration Unit. We also used data from the Swedish National Board of Health and Welfare's national patient register and causes of death register.

Results The study results show significant decreases in outpatient visits from 130.5/1,000 to $107.2 / 1,000$ (18 per cent) in Falkoping and from 143.9/1,000 to 88.8/1,000 (38 per cent) in Lidkoping. Available data from comparison communities in the south and mid-north of Sweden, the surrounding district of the study areas, and Sweden as a whole, showed increasing number of outpatient visits. No significant changes were shown for mortality or hospitalisation in the study areas.

Conclusions This study points to the importance of more systematic collection data of injury events treated at the outpatient level, particularly for communities where there are relatively low numbers of injury-related deaths and hospitalizations. It also shows that long-term action- programs can be successfully.

\section{Child Safety}

\section{Parallel Tue 1.2}

\section{EVALUATION OF 'SAFE HOME SAFE KIDS': A HOME VISITING PROGRAM FOR ABORIGINAL AUSTRALIAN CHILDREN}

Kathleen Clapham, Keziah Bennett-Brook. Australian Health Service Research Institute, University of Wollongong, Australia

\subsection{6/injuryprev-2016-042156.235}

Background Research reveals consistently higher injury rates amongst Aboriginal Australian children (AIHW: Pointer 2014). Intervention strategies for this population must be culturally appropriate and take into account a broad range of social, historical and cultural factors impacting on Aboriginal health and safety, however few culturally acceptable interventions have been 